\title{
Diversidade de maçãs (Malus Domestica Borkh.) nas Feiras de produtores de Nova Iorque
}

\section{Apple (Malus domestica Borkh.) diversity in farmers market of New York}

Gutemberg Armando Diniz Guerra - Doutor em Socioeconomia do Desenvolvimento pela École des Hautes Etudes en Sciences Sociales, Professor Associado do Núcleo de Ciências Agrárias e Desenvolvimento Rural da Universidade Federal do Pará, Belém-PA. Email: gguerra@ufpa.br

Lin Chan Ming - Doutor em Ciências Biológicas pela Universidade Estadual Paulista Júlio de Mesquita, Professor do Departamento de Produção Vegetal do Setor Horticultura da Faculdade de Ciências Agronômicas da Universidade Estadual Paulista - Botucatu-SP. Email: linming@fca. unesp.br

Maria de Nazaré Angelo Menezes - Doutora em História Agrária pela École des Hautes Études en Sciences Sociales, Professora do Núcleo de Ciências Agrárias e Desenvolvimento Rural da Universidade Federal do Pará - Belém-PA. Belém-PA. Email: mnam@ufpa.br

\section{Resumo}

Visitando feiras de produtores locais na cidade de Nova Iorque por um ano, entre junho de 2008 e maio de 2009 , verificou-se significativa amplitude varietal das maçãs, demonstrandose um aspecto particular da diversidade vegetal. Evidenciadas no verão pela presença volumosa, é no outono e inverno que se nota a diversidade intraespecífica, atravessando todos os períodos sazonais. Verificou-se a existência de mais de quatro centenas de espécies vegetais disponíveis no mercado, escolhendose a maçã como um dos tipos mais evidentes para a análise da diversidade, uma vez que se oferecem em 65 cultivares nas feiras do estado ao qual emprestam o apelido. Representam um tipo de diversidade que extrapola ao conceito de especialização, usualmente atribuído à agricultura dos países desenvolvidos, uma vez que convivem com outras espécies nos espaços em que são cultivadas. O objetivo deste artigo é demonstrar a diversidade genética e de usos das maçãs que se expressa na atividade comercial exercida nas ruas e praças novaiorquinas.

\section{Palavras-chave}

Maçã. Mercado do produtor. Etnobotânica. Comércio.

\begin{abstract}
Visiting local growers fairs of New York City during a year, ranging from June, 2008 to May, 2009, a significative number of apple varieties was verified, demonstrating one particular aspect of plant diversity. Offered in Summer with great availability, is in Autumn and Winter that intraspecific diversity can be observed, crossing all seasonal periods. More than four hundred of plant species were verified in the market, choosing apple as one of more evident to analysis of diversity, once it is offered in 65 cultivars in fairs of the State to which the fruit gives the nickname. They represent a kind of diversity that goes beyond the concept of specialization which is usually attributed to agriculture in developed country. The aim of this article is to demonstrate the genetic diversity and use of apples that are expressed in commercial activities in the streets and squares of New York City.
\end{abstract}

\section{Keywords}

Apple. Greenmarket. Fairs. Ethnobotany. Trade. 


\section{INTRODUÇÃO}

Pertencente à família Rosaceae, a maçã (Malus domestica Borkh.) tem como sua ancestral Malus sieversii (Ledeb.) M. Roem., originária da Ásia Central ou Sudeste (TWISS, 1999), provavelmente do Cazaquistão, com o seu centro de diversidade no leste da Turquia. Outros autores indicam que é um complexo de híbridos, envolvendo $M$. pumila com $M$. sylvestris e $M$. mitis (BIGGS, McVICAR \& FLOWERDEW, 2006) ou $M$. sieversii, $M$. orientalis e $M$. sylvestris (VAN WIK, 2006). É árvore de pequeno porte, decídua, variando seu tamanho entre 3 e 12 metros. Cultivadas desde 1500 a. C., foram trazidas para a Inglaterra pelos romanos que as consideravam muito azedas, o que lhes fez estimular o melhoramento por cruzamentos e enxertias (TWISS, 1999). Teriam sido trazidas para os Estados Unidos no século XVII pelos colonizadores europeus, tendo-se como notícia de primeiro plantio no continente o ano de 1625, próximo a Boston.

Considerada uma das primeiras culturas domesticadas (BRAMLAGE, 2001), a maçã está presente na história de civilizações como a grega e a judaicocristã. Ainda que seja a figueira a primeira planta citada na Bíblia (MOLDENKE \& MOLDENKE, 1952), a associação da macieira com a árvore do conhecimento nas Sagradas Escrituras no Livro do Gênesis é um dos elementos mais fortes de sua popularização, favorecida pela adaptabilidade em larga faixa do planeta, sua capacidade de conservação por longos períodos e pela possibilidade de seu transporte por longas distâncias.

Nas feiras de Nova Iorque pode-se encontrar maçãs ao longo de todo o ano, ofertadas para usos diversos. Este artigo descreve e analisa a presença desta fruta nas feiras de produtores desta metrópole americana, as cultivares encontradas e os usos que delas podem fazer.

\section{MERCADO DE CULTIVARES VEGETAIS: A EMPIRIA.}

As feiras de produtores de Nova Iorque (Greenmarket farmers) são feiras ao ar livre armadas em pontos estratégicos da cidade, ao longo do ano, para vendas de produtos agrícolas pelos próprios agricultores. Caracterizam-se fundamentalmente por ser mercados de produtores de uma área de abrangência restrita, em contato direto com os consumidores da cidade de Nova Iorque, entendida neste texto como os cinco $\operatorname{condados}^{1}$ que a compõem.

A produção de maçã e o uso de produtos químicos que possam comprometer a sua qualidade biológica vem sendo equacionada sistematicamente, conforme se pode depreender das atas dos congressos sobre a cultura (LINCHY \& PRANGE,

Na divisão administrativa dos Estados americanos as cidades são divididas em condados, sendo que a de Nova Iorque possui cinco: Manhattan, Queens, Brooklin, Bronx e Staten Island. Embora alguns traduzam como bairros, o termo não corresponde ao equivalente em português.

Novos Cadernos NAEA, v. 16, n. 1, Suplemento, p. 89-108, jun. 2013 
2007) e de literatura produzida sobre as formas de produção (AMES, 2001). Este é um esforço que demonstra a preocupação de produtores que não assumiram o fomento advindo com a Revolução Verde na década de 1970, ou que passaram a questioná-la pelos efeitos colaterais promovidos no processo de modernização da agricultura como fenômeno do pós Segunda Guerra Mundial.

Os produtores de maçã novaiorquinos possuem uma organização que lhes patrocina a publicidade, acessível em site especifico ${ }^{2}$ em que pode-se ter as informações sobre o vegetal e os usos que dele se podem fazer. Outras organizações de caráter corporativo, científico ou vegetariano apregoam as virtudes desta espécie tanto nos Estados Unidos quanto na Inglaterra (MINISTRY OF AGRICULTURE, FISHERIES AND FOOD, 1958; AN APPLE A DAY, 2009; APPLES KEEP YOUR FAMILY HEALTHY, 2009). Além disso, a literatura sobre maçãs é abundante e muito significativa no aspecto que trata das variedades e seus benefícios para a saúde (BLANK, 1996; BOYER, 2004; CHAN; GRAVES \& SHEA, 2006), ou orientam para as melhores variedades a serem adquiridas ou plantadas (HANSON, 2005).

\section{REVISÃO BIBLIOGRÁFICA}

Brochura publicada em 1981, ao recontar brevemente a história das maçãs nos Estados Unidos, aponta o fato de que o melhoramento incrementado no século XX relegou ao segundo plano variedades antigas e selvagens muito saborosas, dando prioridade a variedades mais bonitas, porém menos interessantes no aspecto sabor. Este mesmo texto descreve 21 variedades classificando-as em precoces e tardias (APPLES FOR EVERYONE, 1981). Warren (1995) descreve em texto ilustrado com fotografias 50 cultivares que considera servirem de referência nos pomares, tanto para o mercado varejista atual como para o futuro. Bultidude (s/d), em seu ilustrado Guia para identificação de variedades internacionais apresenta nada menos que 252 variedades. Estas e outras publicações, feitas ao longo de mais de dois séculos, se detiveram na descrição detalhada das maçãs ${ }^{3}$, demonstrando a enorme importância alimentar que este cultivo tem na cultura dos países do norte. A diferenciação minuciosa se dá pelo fruto mas também por todas as partes da planta (SHAW, 1922 e 1943). Um cuidadoso levantamento das variedades citadas nas publicações, entre 1804 e 1904, feito por Ragan (1905), listou mais de 1400 variedades. Twiss (1999) informa que no Brogdale Horticultural Trust, em Kent, na Inglaterra, se encontram mais de 2400 variedades de maçãs em uma coleção que serve para estimular os produtores a

New York Apple Country: http://www.nyapplecountry.com.

3 Ver também Sicol (1831), Martin (1976), Warder (1867), Twiss (1999), Apples and pears (1958); Bultitude (s/d); Taylor (1948).

Novos Cadernos NAEA, v. 16, n. 1, Suplemento, p. 89-108, jun. 2013 
experimentar as existentes e promover novos cruzamentos. É a maior coleção de variedades desta espécie existente no mundo. Deve-se notar que nesta literatura a preocupação com a descrição das variedades está sempre associada aos seus usos gastronômicos, mas também folclóricos e culturais ao longo de toda a história da humanidade (WINNE, 1975; WILSON \& GILLESPIE, 1999; ELLIS DAVIDSON, 1965; RUCK, STAPLES \& HEINRICH, 2001).

Embora seja a figueira a primeira planta citada na Bíblia (MOLDENKE \& MOLDENKE, 1952), a representação da macieira como planta sagrada se difundiu em todo o mundo e tem sido abundante na iconografia e literatura em todos os quadrantes do planeta (MARTIN, 1976). No caso bíblico, foram levantadas dúvidas se as frutas ali contidas são de fato as que podiam-se encontrar na época em que foram escritos os originais, ou se foram dados nomes de plantas subtropicais pelos tradutores gregos e latinos ao trazer o texto para o acesso vernacular (WARDER, 1867).

Conhecida entre os romanos, gregos e persas, a maçã se difundiu nas regiões de clima temperado, onde é importante como alimento desde períodos ancestrais, que remontam aos 2500 a. C., conforme se pode verificar pela sua presença no túmulo da Rainha Pu-abi, encontrado em Ur, no Iraque (JUNIPER \& MABBERLEY, 2006).

Cultivadas tanto em jardins de palácios sofisticados quanto em pomares de famílias modestas, sua difusão na Europa está ligada à expansão da ocupação romana nos séculos I a III d. C. Autores defendem sua ancestralidade na Europa e Ásia, a partir do cruzamento entre maçãs selvagens conhecidas como "crab" (WINNE, 1975; HOGG, 1858). O cultivo e enxertia feitos desde muito tempo nesta cultura foi descrito e ensinado em livro intitulado De Agricultura escrito por Marcus Portius Cato, no século II d. C., praticamente definindo este procedimento por séculos (WINNE, 1858). Outro que deixa descrições importantes sobre o cultivo das maçãs no século I do Império Romano é Caius Plinius Secundus, em sua Historia Naturalis. Embora cite 36 variedades de maçãs, os analistas consideram que se tratavam de frutos silvestres do tipo "crab" (WINNE, 1858). A diversidade impera no cultivo da maçã desde tempos remotos.

A utilização das maçãs na Europa teve menor aproveitamento do que os romanos teriam feito durante o seu período de domínio. Winne (1858) levanta a hipótese do arrefecimento da utilização da maçã nos países europeus cristãos por conta da associação mística com a perda do paraíso. O fato é que os registros do preparo de receitas alimentícias permitiram a retomada e a expansão da utilização da maçã em vasto espectro espacial do planeta (IVES, 1847; SHAW, 1943; SANDERS, 1998).

A vinda da maçã para os Estados Unidos aconteceu pelas navegações de ingleses e franceses, depois do século XVI, consolidando-se ao longo da história do país e influenciando o uso destas em todos os continentes.

Novos Cadernos NAEA, v. 16, n. 1, Suplemento, p. 89-108, jun. 2013 
Nos Estados Unidos as primeiras variedades introduzidas, originalmente por sementes, foram substituidas por aquelas trazidas da Europa - já melhoradas. No Oeste de Nova Iorque, as variedades existentes chegaram pelos estados vizinhos de Connectitut e Massachussets, e depois a Michigan, Norte de Illinois, Wisconsin e Iowa (WARDER, 1867). Parte de uma coleção de 22 variedades foi encontrada, em 1846 no Estado de Connectitut, no Leste dos Estados Unidos (WARDER, 1867), antes do processo de expansão, com variedades melhoradas trazidas no século XX.

A enorme diversidade da espécie exigiu a catalogação por registros de uso, que se encontra disponível desde o século XIX (SICOL, 1831). A Horticultural Society of London publicou catálogo de frutas em que a maçã consta com 1400 variedades caracterizadas pela forma, cor, tamanho, sabor, usos na culinária (tanto para mesa, cozinha), fazer cidras, a qualidade e estações em que estão disponíveis (SICOL, 1831; LAURI, 2006).

As maçãs estão de tal maneira arraigadas na cultura gastronômica dos países de clima temperado que podem ajudar a contar a história social do homem, como demonstra Twiss (1999).

\section{MAÇÃS NA BIG APPLE}

Nova Iorque é o estado que oferece maior variedade comercial de maçã, com inovações feitas nos pomares sendo apregoadas como uma característica do produtor novaiorquino, um dos mais refinados na produção e no sistema de embalagem e conservação das frutas (WELCOME, 2008). O site dos produtores de maçãs (Idem) é muito mais informativo do que vai ser explorado neste artigo, preferindo-se cotejar as informações ali colocadas com o que se pode observar no local da comercialização.

Figura 1. Principais estados produtores de maçã nos Estados Unidos (em vermelho).

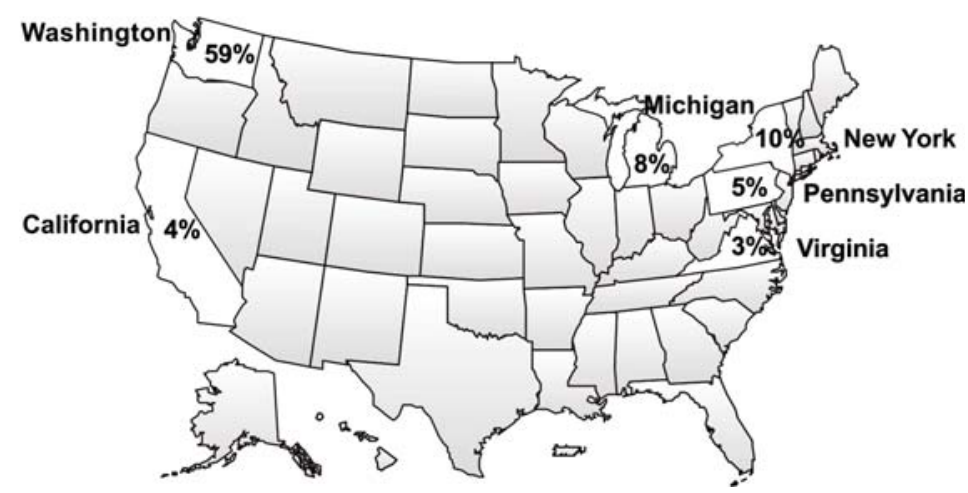

Fonte: WORLD, 2006.

Novos Cadernos NAEA, v. 16, n. 1, Suplemento, p. 89-108, jun. 2013 
O relatório de 2005/2006 da FAO (Food and Agriculture Organization) aponta os Estados Unidos como o maior produtor mundial de maçã, contribuindo com 7\% do volume no mercado mundial, ou seja 4,5 dos 63 milhões de toneladas produzidos naquele ano comercial (USDA/FAS, 2006). O site dos produtores de maçãs (WELCOME, 2008) informa que eles têm aperfeiçoado seus produtos há três séculos e que algumas delas dão, aos consumidores, vontade de experimentálas. É de lá também que existe a informação de que o Estado de Nova Iorque produz 910 milhões de litros por ano, fazendo-o o segundo maior produtor desta fruta no país. O Departamento de Agricultura dos Estados Unidos demonstra que, em 2005, o Estado de Washington continuava na liderança, com 59\% da produção, seguido por Nova Iorque com 10\%, vindo em seguida Michigan, com $8 \%$, conforme se pode verificar na figura 1 (USDA, 2006). Além disso, importantes centros de pesquisas agronômicas desta cultura econtram-se no Estado de Nova Iorque, contribuindo há muito tempo para o desenvolvimento de diferentes variedades para satisfazer aos mais requintados e exigentes paladares da população.

\section{MATERIAL E MÉTODOS}

Foram realizadas visitas desde junho de 2008 até maio de 2009, cobrindo todos os 45 pontos de venda de Nova Iorque em que se observavam ocorrências comuns a este tipo de mercado, seguindo um calendário distribuído pelo Conselho de Meio Ambiente da Cidade de Nova Iorque indicando as localizações e dias de ocorrência ao longo das estações e do ano. As feiras eram realizadas durante o dia, cobrindo em geral a manhã e parte da tarde.

Todas as variedades encontradas nesses pontos de venda foram fotografadas, as informações de suas placas de venda anotadas, bem como qualquer outra informação escrita disponibilizada nas feiras sobre as frutas; foram entrevistados os responsáveis pelos pontos de venda. Foram também realizadas pesquisas em bases de dados existentes sobre a fruta, em páginas eletrônicas, sites de associações de produtores e/ou consumidores da região, livros e artigos científicos sobre maçãs.

Observações exploratórias feitas entre 2003 e 2007, em viagens de reconhecimento, e informações disponíveis no site do programa mantido pelo Council of Environment of New York City, o CENYC (http://www.cenyc.org/ greenmarket/whatsavailable) indicavam tratar-se de um mercado de produtos orgânicos, exclusivo da militância agroecológica, nos moldes do que se pode encontrar nas principais capitais brasileiras (São Paulo, Rio de Janeiro, Brasília, Belo Horizonte, Porto Alegre). O acompanhamento feito durante um ano de pesquisa permitiu verificar que se trata efetivamente de feiras de produtores locais

Novos Cadernos NAEA, v. 16, n. 1, Suplemento, p. 89-108, jun. 2013 
em que se misturam tanto produtores sem certificação como os que assumem o enfoque da agroecologia, agricultura alternativa e outras do gênero, influenciadas pelo movimento ambientalista surgido na década de 70 do século passado.

Os resultados das informações contidas nas placas de venda e no site da Apple Country (WELCOME, 2008) estão organizados na Tabela 1.

\section{RESULTADOS E DISCUSSÃO}

A lista apresentada pelo site dos produtores novaiorquinos é de apenas 30 variedades de maçãs, com os seus respectivos locais de produção e consumo. Pesquisando na literatura sobre esta cultura encontrou-se a listagem e descrição de muitas variedades, confirmando-se diversidade varietal que vai além desta conta. Este aspecto se acentua quando se foca o estudo nas variedades encontradas nas visitas à feira no período referido da pesquisa. Sobre a diversidade, as informações são disponibilizadas desde a própria feira, com placas apresentando dados históricos, morfológicos, de sabor e possibilidades de uso, até uma vasta literatura encontrada nas bibliotecas e livrarias.

A New York Apple Country, entidade que congrega pomicultores da região de Nova Iorque, apresenta um cartaz com as 20 variedades mais difundidas, disponível em seu site (http://www.nyapplecountry.com/varieties. htm), com as denominações utilizadas no Estado de Nova Iorque. Além de apresentar a fotografia de cada variedade de fruto, faz uma descrição das suas principais características, melhores usos, receitas possíveis a partir daquelas características e os períodos em que estão disponíveis no mercado. Esta lista é complementada com outra tabela, menos rica em detalhes, contendo 19 outras variedades, totalizando 39.

Deve-se ressaltar a forma da exposição dos frutos nas feiras, em caixotes separados, ou sobre tabuleiros, com placas indicando o nome da variedade e preço. Os cartazes variam desde os improvisados, manuscritos em pedaços de papelão ou madeira ordinária, até o das fazendas mais organizadas que têm este material produzido em gráfica, com fotografia colorida e uma tabela com informações que incluem o histórico, as principais características e as possibilidades de uso das maçãs. Esta apresentação mais elaborada permitiu identificar não apenas o produto como também o produtor quando do tratamento da fotografia. Além da placa identificando o produto, estas fazendas possuíam caminhões com a logomarca da fazenda com o endereço. Como foram visitadas feiras diferentes em um mesmo dia, pode-se constatar que as fazendas mais prósperas tinham pontos de vendas simultâneos em mais de uma feira no mesmo dia. Foram listadas, por este tratamento, 13 fazendas presentes ofertando maçãs, embora 
as placas sem identificação dificultassem verificar a procedência de todas, o que pode ter implicado em imprecisão, para menos, neste levantamento.

Nas feiras de Nova Iorque, observando e anotando os nomes das que se encontravam em exposição para venda e cotejando com o que se pode encontrar no site, verificou-se a existência de um total de 65 variedades, com a diferença portanto de 26 que não estavam na lista da organização dos produtores. É possível que mais de um nome seja dado para a mesma variedade, ou tenha variações como o uso de diminutivos, ou ainda pela qualificação dada pela cor, pelo uso diferenciado, ou pela percepção diversa sobre uma mesma fruta, duplicando ou aumentando a diversidade de nomes, sem que isso signifique efetivamente uma variação genética.

A apresentação das maçãs variava, com fazendas expondo produtos com cartazes dando as características da fruta, chamando inclusive a atenção para a similaridade ou sinonímia, como é o caso da Mutsu, também conhecida como Crispin, vendidas na Feira em frente à Columbia University e Union Square, pela Samascott Orchard's, no dia 21/02/2009. Outro caso é o da Acey Mac, referida na Tabela 1, encontrada na lista do site All Apple Varieties (2009), com a referência de que ela pode ser a mesma Spartan. Este aspecto de diversidade aparente não é exclusividade da cultura da macieira, conforme se pode atestar para o caso da mandioca na Amazônia Brasileira (EMPERAIRE, PINTON \& SECOND, 1998).

Pelo menos uma das variedades de maçã tem um reconhecimento comercial limitado, sendo ofertada como uma variedade local, nativa, pequenina, de aspecto curioso, denominada crab (caranguejo). Foram encontrados exemplares em poucas feiras, em número reduzido de barracas e volume, por um período limitado ${ }^{4}$. Como já foi visto na revisão de literatura, esta é uma variedade nativa, ancestral daquelas melhoradas que são ofertadas no mercado atual (THOREAU, 1862).

Houve variação dos preços durante o período de visitas, por variedade de maçãs. Existem denominações que variavam os preços para mais e outras para menos ao longo do período estudado, sendo encontradas também diferenças de preços no mesmo dia, em barracas diferentes, entre vendedores vizinhos no espaço físico, sem que isto se constituísse em diminuição aparente da procura por um ou por outro preço, principalmente nos finais de semana, quando as feiras são frequentadas mais intensamente. As variações de preço entre produtores podem ser explicadas pela aparência do produto e pelo volume ofertado por eles, variável em função do porte dos estabelecimentos. No verão, quando a safra da maioria das maçãs ocorre, os preços são mais baixos pela maior disponibilidade, com promoções para venda em sacos com as variedades mais abundantes. No inverno o preço sofre um incremento sensível, dada a disponibilidade restrita.

\footnotetext{
4 Registro feito em fotografia para uma ocorrência em 30 de agosto de 2008, em Feira armada na $57^{\text {th }}$ st com 9 a. Av.
}

Novos Cadernos NAEA, v. 16, n. 1, Suplemento, p. 89-108, jun. 2013 
O aspecto visual, compreendendo-se nele o formato do fruto, a cor, brilho e desenho da casca, variando de verde ao vermelho escuro, passando por tonalidades amareladas; a textura da polpa, referida pelo grau de resistência maior ou menor à apreensão; o sabor variando do doce ao ácido, a presença de suco e umidade, e o perfume que desprendem, são consideradas características positivas da maçã para a comercialização. Estas características se incorporam ao nome comercial do produto, servindo de sinalização para a destinação que os consumidores venham dar à sua compra. São estas características que aparecem nas tabuletas/placas, juntamente com o nome e preço, nos tabuleiros das barracas de produtores/feirantes estudados.

\section{COMERCIALIZAÇÃO E USOS DA MAÇÃ NAS FEIRAS}

Vendida em sua maior parte in natura, as maçãs se prestam a variadas formas de uso. Desde o consumo da fruta diretamente, até a sua desidratação, elas podem ser usadas na fabricação de molhos (applesauce), de sucos, de "cider" (uma bebida feita de maçãs prensadas e fermentada), geléias, massas ao forno, pães, tortas e sorvetes. Cada uma das suas aplicações depende de suas qualidades varietais, o que vêm sendo anunciadas nas feiras como indicativos para a sua melhor utilização. Receitas são elaboradas pelo pessoal do staff do programa organizador das Feiras de Produtores, que cumprem um papel fundamental na difusão de conhecimentos sobre o uso de cada espécie e variedade, seja de maçã seja de outros produtos presentes no mercado. Cumprem, assim, um papel de difusores de conhecimentos sobre cada um dos produtos e suas variedades e de estímulo à alimentação saudável. No caso das maçãs vendidas nas feiras visitadas, era comum se ter a degustação de fatias dos frutos das variedades em oferta, constituindo-se praticamente em um procedimento comum ao mercado deste produto, imprimindo à feira um caráter de sociabilidade ampliada. Além da degustação, as pessoas eram estimuladas ao comentário entre si e à compra das mais apreciadas.

A variação nos nomes são um indicativo importante tanto da variedade existente na espécie como das possibilidades de uso de uma mesma espécie. Para efeito de fornecer uma visualização sistemática do observado nas feiras novaiorquinas, a Tabela 1 vem com o número de variedades identificadas pelo nome comercial com o qual se apresentou e dados observados quando da coleta da informação ou a posteriori, na literatura disponível em bibliotecas ou em web sites. Foi efetuada tradução do encontrado para definição das características, tentandose preservar ao máximo a possibilidade de verificação in loco. As indicações de preço, em dólares americanos, foram feitas em libra, que corresponde a 453g. 
Tabela 1. Variedades de maçãs encontradas nas feiras de produtores de Nova Iorque, no período de Junho de 2008 a Maio de 2009.

\begin{tabular}{|c|c|c|c|c|}
\hline $\mathbf{N}^{\circ}$ & $\begin{array}{c}\text { Variedade } \\
\text { Nome comercial } \\
\end{array}$ & Origem & $\begin{array}{c}\text { Disponível } \\
\text { na feira }\end{array}$ & Características \\
\hline 01 & Acey Mac & Nova Iorque & $\begin{array}{l}\text { Setembro a } \\
\text { Junho }\end{array}$ & $\begin{array}{l}\text { Crocante, suculenta e doce, } \\
\text { embora apresente acidez. } \\
\text { Consumida crua, em lanche } \\
\text { e em molhos e tortas. }\end{array}$ \\
\hline 02 & Ambrosia & Canadá $^{1}$ & $\begin{array}{l}\text { Outubro a } \\
\text { Janeiro }\end{array}$ & $\begin{array}{l}\text { Crocante, suculenta, } \\
\text { doce, interior amarelado, } \\
\text { levemente aromática. }\end{array}$ \\
\hline 03 & Baldwin & $\begin{array}{l}\text { Wilmington, } \\
\text { Massachussets, } \\
\text { EUA }^{2}\end{array}$ & $\begin{array}{l}\text { Outubro a } \\
\text { Abril }\end{array}$ & $\begin{array}{l}\text { Ácida. Consumida crua, em } \\
\text { molhos, massas e tortas. }\end{array}$ \\
\hline 04 & Black twig & $\begin{array}{l}\text { Tenessee ou } \\
\text { Alabama, EUA }\end{array}$ & Novembro & Levemente ácida e crocante. \\
\hline 05 & Braeburn & Nova Zelândia ${ }^{4}$ & $\begin{array}{l}\text { Abril a } \\
\text { Outubro }\end{array}$ & $\begin{array}{l}\text { Doce, sabor ácido, crocante, } \\
\text { lisa, aromática e suculenta, } \\
\text { com a polpa amarela. } \\
\text { Consumida fresca, em } \\
\text { massas, tortas, molhos de } \\
\text { maçã, como aperitivo e } \\
\text { salada }\end{array}$ \\
\hline 06 & Cameo & $\mathrm{EUA}^{5}$ & $\begin{array}{l}\text { Abril até final } \\
\text { de outubro }\end{array}$ & $\begin{array}{l}\text { Doce, firme, crocante } \\
\text { suculenta. Sabor tártaro. } \\
\text { Casca fina com listas } \\
\text { vermelhas brilhantes e cor } \\
\text { laranja-creme. Consumida } \\
\text { fresca, em saladas, tortas, } \\
\text { molhos e assados. }\end{array}$ \\
\hline 07 & Chipper & 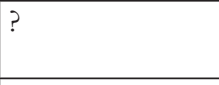 & Novembro & $\begin{array}{l}\text { Doce. Coloração amarela e } \\
\text { vermelho claro. }\end{array}$ \\
\hline 08 & Cortland & Nova Iorque $^{6}$ & $\begin{array}{l}\text { Setembro a } \\
\text { Abril }\end{array}$ & $\begin{array}{l}\text { Doce com um toque de } \\
\text { acidez. Suculenta, tenra, } \\
\text { polpa como neve branca. } \\
\text { Consumida diretamente, } \\
\text { em saladas, molhos, tortas, } \\
\text { massas e congelados. Não } \\
\text { escurecem rapidamente } \\
\text { quando cortadas. }\end{array}$ \\
\hline 09 & Crab & Europa & Agosto & $\begin{array}{l}\text { Maçã pequenina, crocante, } \\
\text { ácida. }\end{array}$ \\
\hline
\end{tabular}

\footnotetext{
Orange Pippin, 2010 .

Warder, 1867, p. 421 e Bultitude, s.d., p. 83.

Ragan, 1905, p. 47.

Yepsen, 1994, p. 80.

5 Orange Pippin, 2010b.

6 Yepsen, 1994, p. 90
}

Novos Cadernos NAEA, v. 16, n. 1, Suplemento, p. 89-108, jun. 2013 


\begin{tabular}{|c|c|c|c|c|}
\hline $\mathbf{N}^{\circ}$ & $\begin{array}{c}\text { Variedade } \\
\text { Nome comercial } \\
\end{array}$ & Origem & $\begin{array}{c}\text { Disponível } \\
\text { na feira }\end{array}$ & Características \\
\hline 10 & $\begin{array}{l}\text { Crispin } \\
\text { (também conhecida } \\
\text { como Mutzu ou } \\
\text { Crispen) }\end{array}$ & Japão & $\begin{array}{l}\text { Outubro a } \\
\text { Setembro }\end{array}$ & $\begin{array}{l}\text { Doce, suculenta, crocante. } \\
\text { Consumida in natura, em, } \\
\text { saladas, molhos, assados, } \\
\text { congelados e tortas. }\end{array}$ \\
\hline 11 & Early MacIntosh & $\begin{array}{l}\text { Geneva, Nova } \\
\text { Iorque, EUA? }\end{array}$ & $\begin{array}{l}\text { Agosto a } \\
\text { Outubro }\end{array}$ & $\begin{array}{l}\text { Muito parecida com Melba } \\
\text { e McIntosh, sabor suave de } \\
\text { morango, suculenta, macia, } \\
\text { interior branco. }\end{array}$ \\
\hline 12 & Empire & $\begin{array}{l}\text { Geneva, Nova } \\
\text { Iorque }^{8}\end{array}$ & $\begin{array}{l}\text { Setembro a } \\
\text { Agosto }\end{array}$ & $\begin{array}{l}\text { Agridoce, suculenta e } \\
\text { crocante com o interior } \\
\text { branco-creme. Consumida } \\
\text { em saladas e in natura; em } \\
\text { molhos, assados, tortas e } \\
\text { congelados. }\end{array}$ \\
\hline 13 & Fortune & Bedford, Inglaterra & $\begin{array}{l}\text { Setembro a } \\
\text { Junho }\end{array}$ & $\begin{array}{l}\text { Sabor doce e ácido. Consumo } \\
\text { in natura, molhos, tortas. }\end{array}$ \\
\hline 14 & Freedom & Nova Iorque, EUA ${ }^{9}$ & Outubro & $\begin{array}{l}\text { Saborosa, suculenta e } \\
\text { deliciosa. Semelhante a } \\
\text { MacIntosh. }\end{array}$ \\
\hline 15 & Fuji & Japão & $\begin{array}{l}\text { Outubro a } \\
\text { Junho }\end{array}$ & $\begin{array}{l}\text { Doce, suculenta e crocante } \\
\text { com miolo cor de creme. } \\
\text { Consumida como aperitivo in } \\
\text { natura e saladas; em molhos. }\end{array}$ \\
\hline 16 & Gala & Nova Zelândia & $\begin{array}{l}\text { Setembro a } \\
\text { Junho }\end{array}$ & $\begin{array}{l}\text { Doce, com brilho vermelho- } \\
\text { amarelado. Suculenta. } \\
\text { Crocante, com interior } \\
\text { amarelo cremoso. Consumo } \\
\text { in natura e salada. }\end{array}$ \\
\hline 17 & Ginger Delicious & $?$ & Agosto & Cor verde clara. \\
\hline 18 & Ginger Gold & Virginia $^{10}$ & $\begin{array}{l}\text { Agosto a } \\
\text { Novembro }\end{array}$ & $\begin{array}{l}\text { Doce, levemente ácida. Fina } \\
\text { textura, interior crocante e de } \\
\text { cor creme. Amadurecimento } \\
\text { precoce. Consumo in natura e } \\
\text { saladas. }\end{array}$ \\
\hline 19 & Golden Delicious & Virginia, EUA ${ }^{11}$ & $\begin{array}{l}\text { Setembro a } \\
\text { Junho }\end{array}$ & $\begin{array}{l}\text { Sabor muito adocicado. } \\
\text { Suculenta. Crocante, interior } \\
\text { amarelo claro. Consumo } \\
\text { in natura, saladas e molhos, } \\
\text { tortas, assados e congelados. }\end{array}$ \\
\hline 20 & $\begin{array}{l}\text { Gold Rush or } \\
\text { Golden Delicious }\end{array}$ & Purdue, EUA ${ }^{12}$ & Novembro & $\begin{array}{l}\text { Crocante e ácida. Para } \\
\text { consumo in natura, em } \\
\text { massas e molhos. }\end{array}$ \\
\hline
\end{tabular}

Wynne, 1975, p. 45.

Yepsen, 1994, p. 98.

Ver http://www.nysaes.cornell.edu/pubs/fls/OCRPDF/103.pdf. Acessado em 01/05/2010.

Ver em http://www.nyapplecountry.com/azapples.htm.

Bultitude, s. d., p. 177; Wynne, 1975, p. 46.

12 Yepsen, 1994, p. 118.

Novos Cadernos NAEA, v. 16, n. 1, Suplemento, p. 89-108, jun. 2013 


\begin{tabular}{|c|c|c|c|c|}
\hline $\mathbf{N}^{\circ}$ & $\begin{array}{c}\text { Variedade } \\
\text { Nome comercial }\end{array}$ & Origem & $\begin{array}{c}\text { Disponível } \\
\text { na feira }\end{array}$ & Características \\
\hline 21 & Golden Russet & Nova Iorque $^{13}$ & $\begin{array}{l}\text { Outubro a } \\
\text { Dezembro }\end{array}$ & $\begin{array}{l}\text { Sabor adocicado. Consumo: } \\
\text { in natura, salada, molho e } \\
\text { torta. }\end{array}$ \\
\hline 22 & Golden Supreme & Oeste da Virgínia ${ }^{14}$ & $\begin{array}{l}\text { Setembro a } \\
\text { Abril }\end{array}$ & $\begin{array}{l}\text { Sabor doce. Consumo in } \\
\text { natura, salada e molho. }\end{array}$ \\
\hline 23 & Greening & Sul dos EUA & Novembro & $\begin{array}{l}\text { Verde claro amarelado. } \\
\text { Ácida. }\end{array}$ \\
\hline 24 & Granny Smith & $\begin{array}{l}\text { Ryde, New South } \\
\text { Wales, Austrália }^{15}\end{array}$ & Novembro & $\begin{array}{l}\text { Ácida e crocante, consumida } \\
\text { em tortas. }\end{array}$ \\
\hline 25 & Honey Crisp & Minessota $^{16}$ & $\begin{array}{l}\text { Setembro a } \\
\text { Fevereiro }\end{array}$ & $\begin{array}{l}\text { Doce com um toque ácido } \\
\text { e crocante. Suculenta. Miolo } \\
\text { amarelo. Consumo in natura, } \\
\text { em saladas, molho, assados e } \\
\text { tortas. }\end{array}$ \\
\hline 26 & Idared & Idaho $^{17}$ & $\begin{array}{l}\text { Outubro a } \\
\text { Agosto }\end{array}$ & $\begin{array}{l}\text { Adocicadamente ácida. } \\
\text { Suculenta. Miolo amaerelo- } \\
\text { esverdeado firme, algumas } \\
\text { vezes em tonalidades } \\
\text { rosadas. Excelente para } \\
\text { molhos, cozidos, assados e } \\
\text { tortas. Consumo in natura, } \\
\text { saladas e congelados. }\end{array}$ \\
\hline 27 & Jersey Mac & Nova Jersey, EUA & Agosto & $\begin{array}{l}\text { Cor escura, levemente } \\
\text { perfumada de morango ou } \\
\text { uva. Doce, derrete na boca, } \\
\text { interior branco-neve. Casca } \\
\text { um pouco áspera. }\end{array}$ \\
\hline 28 & Jonagold & Nova Iorque ${ }^{18}$ & $\begin{array}{l}\text { Outubro a } \\
\text { Maio }\end{array}$ & $\begin{array}{l}\text { Doce, excelente sabor. } \\
\text { Ligeiramente ácida. } \\
\text { Suculenta, crocante. Miolo } \\
\text { amarelo cremoso. Consumo } \\
\text { in natura e cozidos e assados, } \\
\text { saladas, molhos, tortas e } \\
\text { congelados. }\end{array}$ \\
\hline 29 & Jonamac & $\begin{array}{l}\text { Geneva, Nova } \\
\text { Iorque, EUA }{ }^{19}\end{array}$ & $\begin{array}{l}\text { Setembro a } \\
\text { Abril }\end{array}$ & $\begin{array}{l}\text { Sabor doce, levemente ácido. } \\
\text { Consumo in natura, molho. }\end{array}$ \\
\hline 30 & Jonathan & $\begin{array}{l}\text { Ulster County, Nova } \\
\text { Iorque }^{20}\end{array}$ & $\begin{array}{l}\text { Setembro a } \\
\text { Abril }\end{array}$ & $\begin{array}{l}\text { Levemente ácido, de sabor } \\
\text { agradável. Consumo in } \\
\text { natura, saladas, molho, tortas. }\end{array}$ \\
\hline 31 & Keepsake & Minnesota, EUA' ${ }^{21}$ & $\begin{array}{l}\text { Outubro e } \\
\text { Novembro }\end{array}$ & Avermelhada. \\
\hline
\end{tabular}

13 Hanson, 2005.

14 Ver http://www.boyernurseries.com/fruit_trees/apples/golden_supreme.html. Acessado em 01/05/2010.

15 Bultitude, s. d., p. 180.

16 Hanson, 2005, p. 53.

17 Bultitude, s. d., p. 199.

18 Bultitude, s. d., p. 205.

19 Yepsen, 1994, p. 146.

20 Bultitude, s. d., p. 206.

Novos Cadernos NAEA, v. 16, n. 1, Suplemento, p. 89-108, jun. 2013 


\begin{tabular}{|c|c|c|c|c|}
\hline $\mathbf{N}^{\circ}$ & $\begin{array}{c}\text { Variedade } \\
\text { Nome comercial }\end{array}$ & Origem & $\begin{array}{c}\text { Disponível } \\
\text { na feira }\end{array}$ & Características \\
\hline 32 & Lady & França $^{22}$ & $\begin{array}{l}\text { Novembro a } \\
\text { Dezembro }\end{array}$ & $\begin{array}{l}\text { Doce. Consumida in natura e } \\
\text { em geléias; decorativa. }\end{array}$ \\
\hline 33 & Liberty & $\begin{array}{l}\text { Ohio }{ }^{23} \text { ou Geneva, } \\
\text { Nova Iorque }^{24}\end{array}$ & $\begin{array}{l}\text { Setembro a } \\
\text { Dezembro }\end{array}$ & $\begin{array}{l}\text { Sabor adocicado, crocante. } \\
\text { Consumo in natura. }\end{array}$ \\
\hline 34 & Lodi & $\begin{array}{l}\text { Geneva, Nova } \\
\text { Iorque }^{25}\end{array}$ & $\begin{array}{l}\text { Julho a } \\
\text { Setembro }\end{array}$ & $\begin{array}{l}\text { Sabor levemente ácido, de } \\
\text { sabor agradável. }\end{array}$ \\
\hline 35 & $\begin{array}{l}\text { McIntosh/ } \\
\text { Macintosh/Mac }\end{array}$ & $\begin{array}{l}\text { Dundas County, } \\
\text { Canadá }^{26}\end{array}$ & $\begin{array}{l}\text { Setembro a } \\
\text { Junho }\end{array}$ & $\begin{array}{l}\text { Doce com sabor levemente } \\
\text { ácido. Vermelha com pontos } \\
\text { amarelados, macia, com } \\
\text { interior branco. Consumo in } \\
\text { natura e molho. }\end{array}$ \\
\hline 36 & Macoun & $\begin{array}{l}\text { Geneva, Nova } \\
\text { Iorque }^{27}\end{array}$ & $\begin{array}{l}\text { Outubro a } \\
\text { Novembro }\end{array}$ & $\begin{array}{l}\text { Crocante, doce, suculenta } \\
\text { e macia. Aromática. Miolo } \\
\text { branco-neve. Consumo in } \\
\text { natura, em molhos e saladas. }\end{array}$ \\
\hline 37 & Monroe & $(\mathrm{O} .)^{28}$ & $\begin{array}{l}\text { Outubro a } \\
\text { Dezembro }\end{array}$ & $\begin{array}{l}\text { Levemente ácida e doce, } \\
\text { sabor agradável. Consumo } \\
\text { in natura, salada, molho e } \\
\text { assados. }\end{array}$ \\
\hline 38 & $\begin{array}{l}\text { Mutzu (Crispen ou } \\
\text { Crispin) } \\
\end{array}$ & Japão ${ }^{29}$ & Novembro & $\begin{array}{l}\text { Crocante, muito doce, } \\
\text { excelente para tortas. }\end{array}$ \\
\hline 39 & Mutzu's Mother & $?$ & Novembro & $\begin{array}{l}\text { Crocante e adocicada. } \\
\text { Consumo in natura, saladas e } \\
\text { assados. }\end{array}$ \\
\hline 40 & Newton Pippin & Long Island, EUA ${ }^{30}$ & $\begin{array}{l}\text { Outubro a } \\
\text { Dezembro }\end{array}$ & $\begin{array}{l}\text { Doce e levemente ácida. } \\
\text { Consumo in natura, em } \\
\text { saladas e assados. }\end{array}$ \\
\hline 41 & Northern Spy & $\begin{array}{l}\text { Rochester, Nova } \\
\text { Iorque }^{31}\end{array}$ & $\begin{array}{l}\text { Outubro a } \\
\text { Dezembro }\end{array}$ & $\begin{array}{l}\text { Levemente ácida, com } \\
\text { sabor agradável. Consumo } \\
\text { in natura, molhos, assados, } \\
\text { tortas e congelados. }\end{array}$ \\
\hline 42 & Paula Red & Michigan $^{32}$ & $\begin{array}{l}\text { Final de } \\
\text { Agosto até } \\
\text { Outubro }\end{array}$ & $\begin{array}{l}\text { Levemente ácida, com sabor } \\
\text { agradável. Suculenta. Miolo } \\
\text { branco. Consumo in natura e } \\
\text { em molhos. }\end{array}$ \\
\hline 43 & Pink Lady & Austrália ${ }^{33}$ & Novembro & $\begin{array}{l}\text { Crocante, levemente ácido e } \\
\text { com sabor agradável. }\end{array}$ \\
\hline
\end{tabular}

Yepsen, 1994, p. 152.

Warder, 1867, p. 411; Yepsen, 1994, p. 162.

Warder, 1867, p. 724.

Yepsen, 1994, p. 164.

Bultitude, s. d., p. 227.

Bultitude, s. d., p. 240.

Wynne, 1975, p. 49.

Warder, 1867, p. 726.

Yepsen, 1994, p. 176.

Warder, 1867, p. 727 e Bultitude, s. d., p. 255.

Warder, 1867, p. 541 e Bultitude, s. d., p. 261.

32 Ver em http://www.nyapplecountry.com/azapples.htm.

Novos Cadernos NAEA, v. 16, n. 1, Suplemento, p. 89-108, jun. 2013 


\begin{tabular}{|c|c|c|c|c|}
\hline $\mathbf{N}^{\circ}$ & $\begin{array}{c}\text { Variedade } \\
\text { Nome comercial }\end{array}$ & Origem & $\begin{array}{c}\text { Disponível } \\
\text { na feira }\end{array}$ & Características \\
\hline 44 & Pinova & Alemanha $^{34}$ & Dezembro & $\begin{array}{l}\text { Sabor levemente equilibrado } \\
\text { de pera após consumo. } \\
\text { Miolo firme. }\end{array}$ \\
\hline 45 & Prestine/Pristine & Purdue, EUA & Agosto & Amarela \\
\hline 46 & Pound Sweet & Michigan? ${ }^{35}$ & Outubro. & $\begin{array}{l}\text { Doce. Consumida em } \\
\text { assados. }\end{array}$ \\
\hline 47 & Quince & Michigan $^{36}$ & Novembro & $\begin{array}{l}\text { Consumida em geléias, } \\
\text { carnes e em tortas. }\end{array}$ \\
\hline 48 & Red Del & $?$ & Novembro & $\begin{array}{l}\text { Doce. Crocante, suculenta, } \\
\text { cor ligeiramente manchada } \\
\text { de rosa. }\end{array}$ \\
\hline 49 & Red Delicious & $\mathrm{EUA}^{37}$ & $\begin{array}{l}\text { Outubro a } \\
\text { Setembro. }\end{array}$ & $\begin{array}{l}\text { Doce, suculenta, crocante, } \\
\text { miolo amarelado. Consumo } \\
\text { in natura e salada. }\end{array}$ \\
\hline 50 & R. I. Greening & Rhode Island ${ }^{38}$ & $\begin{array}{l}\text { Outubro a } \\
\text { Fevereiro. }\end{array}$ & $\begin{array}{l}\text { Levemente ácida com sabor } \\
\text { agradável. Consumida em } \\
\text { molhos, tortas e assados }\end{array}$ \\
\hline 51 & Rome ou Red Rome & Ohio & $\begin{array}{l}\text { Final de } \\
\text { Outubro a } \\
\text { Setembro }\end{array}$ & $\begin{array}{l}\text { Sabor levemente ácido. } \\
\text { Firme, interior levemente } \\
\text { branco-esverdeado. } \\
\text { Consumidas em molho, } \\
\text { assados e tortas, saladas e } \\
\text { congelados. }\end{array}$ \\
\hline 52 & Sonata & $\begin{array}{l}\text { Alemanha/ } \\
\text { Polônia }^{39}\end{array}$ & $\begin{array}{l}\text { Outubro a } \\
\text { Fevereiro }\end{array}$ & Doce levemente ácido. \\
\hline 53 & Sansa & Nova Zelândia ${ }^{40}$ & $\begin{array}{l}\text { Final de } \\
\text { agosto }\end{array}$ & $\begin{array}{l}\text { Crocante, doce, levemente } \\
\text { ácida. }\end{array}$ \\
\hline 54 & Spy & $?$ & & \\
\hline 55 & Spigold ou Spygold. & $\begin{array}{l}\text { Geneva, Nova } \\
\text { Iorque, EUA }{ }^{41} \\
\end{array}$ & $\begin{array}{l}\text { Outubro a } \\
\text { Novembro. }\end{array}$ & $\begin{array}{l}\text { Doce. Consumo in natura, } \\
\text { torta. }\end{array}$ \\
\hline 56 & Stayman Winesap & Kansas, EUA ${ }^{42}$ & $\begin{array}{l}\text { Outubro a } \\
\text { Abril. }\end{array}$ & $\begin{array}{l}\text { Doce levemente ácido } \\
\text { e suculenta. Consumo } \\
\text { in natura, salada, molho, } \\
\text { assados e tortas. }\end{array}$ \\
\hline 57 & Summer Pippin & Nova Iorque & Agosto & Casca verde, ácida. \\
\hline
\end{tabular}

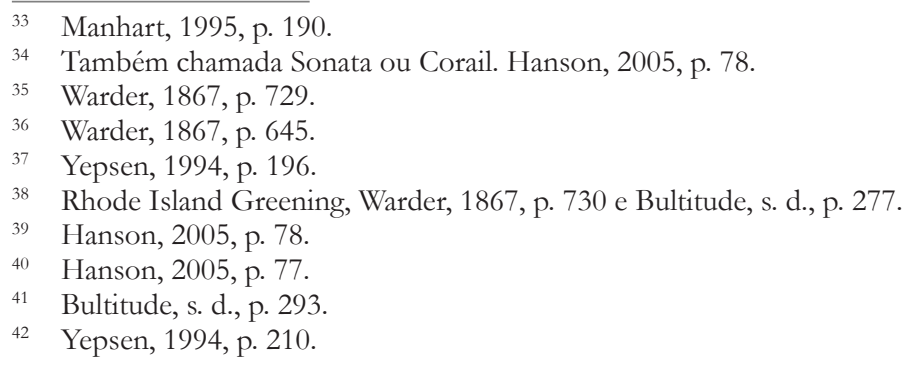

Novos Cadernos NAEA, v. 16, n. 1, Suplemento, p. 89-108, jun. 2013 


\begin{tabular}{l|l|l|l|l}
\hline $\mathbf{N}^{\circ}$ & \multicolumn{1}{|c|}{$\begin{array}{c}\text { Variedade } \\
\text { Nome comercial }\end{array}$} & \multicolumn{1}{|c|}{ Origem } & $\begin{array}{l}\text { Disponível } \\
\text { na feira }\end{array}$ & \multicolumn{1}{c}{ Características } \\
\hline 58 & Suncrisp & P3New Jersey $^{44}$ & $\begin{array}{l}\text { Outubro a } \\
\text { Janeiro }\end{array}$ & $\begin{array}{l}\text { Doce, levemente ácido. } \\
\text { Consumo in natura, assados } \\
\text { e molhos. }\end{array}$ \\
\hline 59 & Twenty ounce & $\begin{array}{l}\text { Nova Iorque e } \\
\text { Connecticut }\end{array}$ & $\begin{array}{l}\text { Setembro a } \\
\text { Novembro }\end{array}$ & $\begin{array}{l}\text { Miolo amarelo-claro. Firme, } \\
\text { suave, suculenta e levemente } \\
\text { ácida. Consumida em tortas, } \\
\text { molhos e assados e cozidos. }\end{array}$ \\
\hline 60 & Tydeman & Kent, Inglaterra & $\begin{array}{l}\text { Agosto a } \\
\text { Setembro }\end{array}$ & Doce. Consumo in natura. \\
\hline 61 & Tydeman Red & Kent, Inglaterra & $\begin{array}{l}\text { Agosto a } \\
\text { Setembro }\end{array}$ & Precoce e doce maçã \\
\hline 62 & Winesap & Nova Jersey, EUA ${ }^{46}$ & $\begin{array}{l}\text { Novembro a } \\
\text { maio }\end{array}$ & $\begin{array}{l}\text { Pesada, suculenta, doce, } \\
\text { levemente ácida e crocante. }\end{array}$ \\
\hline 63 & Winter Banana & $\begin{array}{l}\text { Cass County, } \\
\text { Indiana, EUA }\end{array}$ & $\begin{array}{l}\text { Final de } \\
\text { Setembro e } \\
\text { Outubro }\end{array}$ & Doce, suculenta, aromática. \\
\hline 64 & Yellow Transparent & Rússia ${ }^{48}$ & $\begin{array}{l}\text { Julho a } \\
\text { Setembro }\end{array}$ & $\begin{array}{l}\text { Levemente ácido. } \\
\text { Consumida em tortas. }\end{array}$ \\
\hline 65 & York & Pensilvania, EUA 49 & $\begin{array}{l}\text { Final de } \\
\text { outubro até } \\
\text { abril }\end{array}$ & $\begin{array}{l}\text { Sabor levemente } \\
\text { ácido. Interior } \\
\text { amarelado, consumida } \\
\text { preferencialmente em } \\
\text { molhos e recheio de tortas. }\end{array}$ \\
\hline
\end{tabular}

Como se pode ver na tabela, a descrição dos sabores e das características gastronômicas das maçãs estão associadas ao uso que se pode fazer a partir de sua diversidade. É evidente que a acidez e doçura estão associadas ao frescor e à predileção do consumo da fruta in natura, como se pode ver da indicação feita para a Baldwin, a Braeburn e a Cameo. Verifica-se, entretanto, que estas características não sugerem um uso exclusivo, mas versátil dos frutos, para uso em outras aplicações. A Cortland é anunciada com ressalvas ao fato de resistir à oxidação por mais tempo, mantendo a cor por tempo mais longo após o corte. Ser suculentas, crocantes, ácidas e cheirosas recomendam ao consumo direto, mas também ao uso em saladas, molhos, assados e congelados.

Não está dito em nenhuma das indicações lidas, mas pode-se deduzir que parte destas características está associada às temperaturas e fotoperiodicidade a que estas variedades estão sujeitas, uma vez que não são todas disponibilizadas ao mesmo tempo.

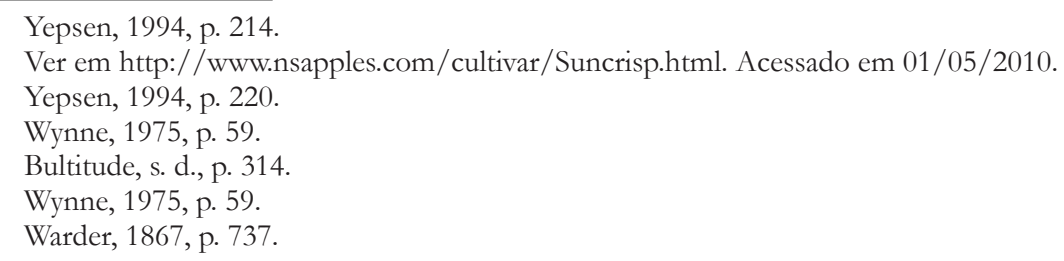


A variação de preços, entre as variedades, não se demonstraram significativas, mas pela maior ou menor disponibilidade na medida em que ia avançando o inverno. $\mathrm{O}$ fato de serem relativamente fáceis de conservar durante o período frio, permite que a sua presença no mercado ocorra praticamente durante todo o ano, mascarando os tempos de safra, se se quiser ter esta referência a partir de suas presenças nos mercados. $\mathrm{O}$ valor econômico de cada cultivar no contexto do mercado novaiorquino está associado ao volume de produção e características de cada um deles de manter-se conservado por um tempo maior para atravessar o período frio, devendo-se reconhecer, entretanto, a preferência pelo sabor. Por este aspecto, algumas variedades se destacam pela procura intensa e frequente, como é o caso da Fuji e da Mutzu/Crispin, presentes no mercado de Outubro até Junho e de Agosto a Novembro, respectivamente.

Elemento importante na análise desta tabela é a variação de cor associada aos nomes e, algumas vezes, aos sabores e preferências. É o caso da Golden Delicious, associada por algumas pessoas ao parentesco com a Red Delicious, mas ela é muito mais suave do que a versão avermelhada. No caso da Tydeman, ora aparece a referência a cor, ora não, ficando a dúvida se se trata da mesma variedade ou não. A tabela é rica em indicações e associações que deveriam ser lidas pelas aplicações e usos históricos que têm sido feitos delas na gastronomia americana, enriquecendo a variedade genética das maçãs com a variedade de usos implementada pelos hábitos e costumes. Deve-se igualmente ter cuidado com indicações sugestivas, uma vez que não existe nelas nenhum caráter de ortodoxia ou interditos nas recomendações de uso. Em princípio, todas estas maçãs podem ser utilizadas conforme entenda o consumidor, em que pese a maior ou menor afinidade que as variedades possam apresentar para um uso ou outro, baseada em suas características morfológicas ou organolépticas.

\section{CONSIDERAÇÕES FINAIS}

Um dos mais ricos elementos das feiras de produtores em Nova Iorque é a possibilidade de troca de informações sobre os usos do que ali é vendido, principalmente pelo caráter multiétnico da cidade, favorecendo um leque ampliado sobre as práticas gastronômicas de um fruto difundido em todo o planeta, como é o caso da maçã. Para os que vêm de climas tropicais, acostumados à biodiversidade interespécies, chama a atenção a riqueza intraespécies, o que se evidencia com este artigo sobre maçãs encontradas em um estado produtor tradicional. Entra em debate outro aspecto da biodiversidade, no caso específico das maçãs, embora surpreendentemente largo, ainda limitado pelo fato de se dar pela reprodução vegetativa e não por via de sementes, o que em muito aumentaria o leque varietal. A comprovação dessa possibilidade se efetiva na leitura científica Novos Cadernos NAEA, v. 16, n. 1, Suplemento, p. 89-108, jun. 2013 
produzida sobre esta cultura, envolvendo recursos para a produção e difusão de conhecimento consideráveis ao longo de toda a história da humanidade.

O levantamento feito ao longo de um ano está longe de ser exaustivo, principalmente considerando a possíbilidade de que haja outras variedades presentes nos estabelecimentos rurais e que não tenham sido consideradas aptas para o comércio. Este aspecto porém não foi explorado no âmbito desta pesquisa.

O viés orgânico sugerido pelo termo Green presente em anúncios e no próprio nome do mercado, deve ser relativizado. O mais forte neste tipo de feira tem sido o apelo ao localismo, entendendo-se este especificamente como uma identidade novaiorquina, demarcada pela chamada de alguns produtos cultivados em uma circunscrição geográfica do Estado de Nova Iorque e outros vizinhos como Connecticut, Massachussets, Pensilvania e New Jersey. O enfoque do local foi se revelando com o avanço da pesquisa e com a análise dos folhetos e catálogos distribuídos pelos funcionários do Conselho de Meio Ambiente que organiza as feiras, nas conversas com os produtores/feirantes e no acesso à literatura pertinente, difundida a partir de experiências do mercado culinário (KINGSOLVER, 2007; POLLAN, 2007). Ponto que reforça esta visão do localismo é o fato de as feiras serem organizadas pelo Conselho de Meio Ambiente da Cidade de Nova Iorque, embora a participação de produtores de municípios e estados vizinhos seja aceita. No caso da cultura da maçã a identidade novaiorquina é reafirmada com o fato de ser a região a segunda maior produtora do país, expressando-se esta identidade no próprio apelido da cidade - Big Apple.

Para uma grande cidade como Nova Iorque, a diversidade de maçãs oferecidas nas feiras permite que sua população possa ter acesso aos tipos trazidos da Europa em tempos mais antigos, bem como as variedades desenvolvidas nos Estados Unidos. As feiras de produtores de Nova Iorque refletem um espectro varietal de maçãs que permite uma visualização diferenciada da agricultura familiar praticada nos Estados Unidos, principalmente, se verificado o fato de que esta diversidade ocorre igualmente em outras culturas e nas mesmas propriedades as quais funcionam como verdadeiros bancos de germoplasma e seus pontos de venda como locais de reflexão e apologia da preservação da biodiversidade do planeta.

A presença extensiva da diversidade de maçãs no Greenmarket traduz, de maneira clara, uma preocupação de preservação da agricultura local, o que se acresce e torna mais evidente no site do Programa do Conselho de Ambiente da Cidade de Nova Iorque, contribuindo para a conservação dessas variedades, muitas delas tradicionais, disponibilizando-as para toda a população da cidade. Foram encontrados nestes dois aspectos, tradição e área de abrangência, expressões da significância das maçãs no tempo histórico e na espacialidade regional, reforçando a importância cultural destes cultivos em Nova Iorque. 


\section{REFERÊNCIAS}

ALL ABOUT Apples Varieties. Disponível em: http://www. allaboutapples. com/varieties/var_a1.htm. Acesso em: 8 maio 2009.

AMES, G. Considerations in organic apple production. National Sustainable Agriculture Information Service, 2001. Disponível em: http://attra.ncat.org/ attra-pub/PDF/omapple.pdf. Acesso em: 5 dez. 2009.

AN APPLE a day keeps the doctor away. Disponivel em: http:/ / www.vegparadise. com/highestperch39.html. Acesso em: 5 dez. 2009.

APPLES for everyone. Mt. Gretna: Preservation Apple Tree Co, 1981. 24p.

APPLES Keep Your Family Healthy. Washington State Apple Advertising Commission. Disponível em: http://www.bestapples.com/healthy. Acesso em: 5 dez. 2009.

BIGGS, M., McVICAR, J., FLOWERDEW, B. Vegetables, herbs \& fruits: an illustrated encyclopedia. Buffalo: Firefl y Books, 2006. 640p.

BLANK, M. (Ed.). Proceedings of the Second Workshop on Pome Fruit Quality. Acta Horticulture. Bonn, International Society for Horticultural Science, $n$. 466, p. 24-26. Nov., 1996.

BOYER, J.; LIU, R. H. Apple phytochemicals and their health benefi ts. Nutrition journal, Ithaca, v. 3, n. 5, 2004. Disponível em: http://www.nutritionj.com/ content/3/1/5. Acesso em: 5 dez. 2009.

BRAMLAGE, W. J. On the Origin of the Edible Apple. Fruit Notes, Massachusetts, v. 66, p. 1-2, 2001. Disponível em: http://www.umass.edu/ fruitadvisor/fruitnotes/ontheorigin.pdf. Acesso em: 5 dez. 2009.

BULTITUDE, J. Apples. A guide to the identifi cation of international varieties. Seattle: University of Washington Press, [s.d.]. 324p.

CARLSON, R. F. et al. North American Apples: Varieties, Rootstocks, outlook. East Lansing: Michigan State University Press, 1970.

CHAN, A; GRAVES, V; SHEA, T. B. Apple juice concentrate maintains acetylcholine levels following dietary compromise. Journal of Alzheimer's Disease, Arlington, v. 9, n. 3, p. 287-291, 2006.

ELLIS DAVIDSON, H. R. Gods and Myths of Northern Europe. London: Penguin Books, 1965. p. 165-166. 
EMPERAIRE, L.; PINTON, F.; SECOND, G. Gestion de la diversité variétale du manioc en Amazonie du nord-ouest, Brésil. Natures, Sciences et Sociétés, Paris, v. 6, n. 2, p. 27-42, 1998.

HANSON, B. The best apples to buy and grow. New York, Brooklyn Botanical Garden Inc., 2005. 120p.

HOGG, Robert. British Pomology. London: Groombridge and sons paternoster Bow, 1858. 306p.

IVES, J. M. New England Book of Fruit. Salem: W. \& S. B. Ives; Boston: W. J. Reynolds; B. B. Mussey, 1847. 143 p.

JUNIPER, B. E.; MABBERLEY, D. J. The story of the Apple. Portland: Timber press, 2006. 379p.

KINGSOLVER, B. Animal, vegetable, miracle. A year of food life. New York: Harper Perennial, 2007. 384 p.

LAURI, P.-É.; MAGUYLO, K.; TROTTIER, C. Architecture and size relations: an essay on the apple (Malus x domestica, Rosaceae) tree. American Journal of Botany, v. 93, p.357-368, 2006.

MANHART, W. Apples for the 21st century. Portland: North America Tree Company, 1995.

MARTIN, A. A. All about apples. Boston: Houghton Miffl in Company, 1976. $174 \mathrm{p}$.

MINISTRY OF AGRICULTURE, FISHERIES AND FOOD. Apples and pears. London: Her Majesty's Stationary Office, 1958. 135p. (Bulletin no. 133).

MOLDENKE, H. N.; MOLDENKE, A. L. Plants of the Bible. New York: Dover Publications Inc., 1952, 387p.

MORGAN, J.; RICHARDS, A. The new book of apples. London: Elbury Press, 2002. 315p.

POLLAN, M. Omnivore's Dilemma. A natural history of four meals. New York: Penguin Group, 2007. 464 p.

RAGAN, W. H. Nomenclature of the apple: a catalogue of the known varieties referred to in American publications from 1804 to 1904. Washington: Government Printing Office. U. S. Department of Agriculture, 1905. 383 p. (Bureau of Plant Industry, Bulletin n. 56). 
RUCK, C.1; STAPLES, B. D; HEINRICH, C. The Apples of Apollo, Pagan and Christian Mysteries of the Eucharist. Durham: Carolina Academic Press, 2001. p. 64-70.

SANDERS, R. The English Apple. Oxford: Phaidon, 1998. 141p.

SHAW, J. K. Descriptions of Apples Varieties. Amherst: Massachusetts Agricultural Experiments Station, 1943. 186p. (Bulletin n. 403).

SHAW, J. K. Leafs Characters of Apple Varieties. Amherst: Massachusetts Agricultural Experiments Station, 1922. 31p. (Bulletin n. 208).

SICOL, W. A catalogue of the fruits cultivated in the garden of the Horticultural Society of London. London: Horticultural Society of London, 1831. 208p.

TAYLOR, H. V. The apples of England. London: Crosby Lockwood \& son, 1948. 218p.

THOREAU, H. D. The wild apple. Bedford: The Atlantic Monthly, 1862. 25 p.

TWISS, S. Apples: a social history. London: National Trust Enterprises Ltd, 1999. 46p.

USDA/FAS Horticultural \& Tropical Products Division. World apple situation and outlook. April 2006. Disponível em: http://www.fl ex-news-food.com/ files/S_WorldAppleSituation\&Outlook_26042006.pdf. Acesso em: 18 dez. 2008.

WARDER, J. A. American Pomology. Apples. New York: Orange Judd and Company, 1867. 744p.

WELCOME to New York Apple Country. Disponível em: http://www. nyapplecountry.com. Acesso em: 10 dez. 2008.

WILSON, D. S.; GILLESPIE, A. K.. Rooted in America. Foodlore of Popular fruits and vegetables. Knoxville: University of Tennessee Press, 1999. 238 p.

WYNNE, P. Apples. History, Folklore, Horticulture, and Gastronomy. New York: Hawthorn Books, 1975. 280p.

YEPSEN, R. Apples. New York; London: W. W. Norton and Company, 1994. 